\title{
Study of retroanalysis of asphaltic pavements resilience modules with the use of artificial neural networks
}

\author{
Alcidney Batista Celeste ${ }^{1}$, Francisco Heber Lacerda de Oliveira ${ }^{2}$ \\ ${ }^{1}$ National Department of Transport Infrastructure, alcidney.batista@dnit.gov.br \\ ${ }^{2}$ Federal University of Ceará, heber@det.ufc.br
}

\section{Recebido:}

13 de julho de 2018

Aceito para publicação:

14 de outubro de 2019

Publicado:

31 de dezembro de 2019

Editor de área:

Kamilla Vasconcelos

\section{Keywords:}

Asphalt pavements,

Resilience module,

Retroanalysis,

Artificial neural networks.

\section{Palavras-chaves:}

Pavimentos asfálticos,

Módulo de resiliência,

Retroanálise,

Redes Neurais Artificiais.

DOI:10.14295/transportes.v27i4.1781

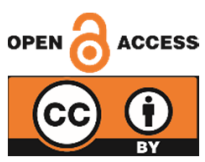

\begin{abstract}
Knowledge of pavement Resilience Modules (RM) is an important element for the structural assessment of existing infrastructures. One way to determine them is through dynamic repeated load testing in the laboratory; another way is to use the technique of retroanalysis, which consists in obtaining the RM from the thickness of the layers and the deflections measured on the pavement surface. In this sense, this paper aims to present the RM retroanalysis through the technique of Artificial Neural Networks (ANN) as an alternative to the traditional retroanalysis. The results demonstrate that the ANN could predict the RM with results of coefficients of determination $\left(R^{2}\right)$ above $99.9 \%$ between the reference and predicted values. Thus, ANN are a potential alternative to obtain this important mechanical property of paving materials compared to traditional methods.
\end{abstract}

\section{RESUMO}

O conhecimento dos Módulos de Resiliência (MR) de pavimentos é elemento importante para a avaliação estrutural das infraestruturas existentes. Uma maneira de determiná-los é através de ensaios dinâmicos de carga repetida, em laboratório; outra forma, é utilizar a técnica de retroanálise, que consiste na obtenção dos MR a partir das espessuras das camadas e das deflexões medidas na superfície do pavimento. Nesse sentido, este artigo tem o objetivo de apresentar a retroanálise dos MR através da técnica de Redes Neurais Artificiais (RNA) como alternativa à retroanálise tradicional. Os resultados demonstraram que as RNA conseguem prever os MR com resultados de coeficientes de determinação $\left(R^{2}\right)$ acima de $99,9 \%$ entre os valores de referência e previstos. Desse modo, as RNA se apresentam como uma alternativa em potencial para a obtenção dessa importante propriedade mecânica dos materiais para pavimentação frente aos métodos tradicionais.

\section{INTRODUCTION}

In Brazil, since the mid-1960s, asphalt pavement highways have been designed using an empirical method that is based on the subgrade's carrying capacity through the California Bearing Ratio. Such method does not consider the influence of the mechanical properties of the constituent materials of the layers underlying the subgrade under the stresses and deformations caused by the loads acting on the surface of the pavement.

With the development of studies and research on new asphalt pavement design methods, the knowledge of the elastic characteristics of the materials used in road paving becomes indispensable. The Resilience Module (RM) is a mechanical property of the material whose knowledge is essential for the use of mechanistic-empirical methods of designing new pavements as well 
as for the structural evaluation of existing pavements, when an evaluation of their lifespan is required.

Material RM has been increasingly used in the country with the purpose of using mechanistic-empirical pavement design methods (Bernucci et al., 2006). The RM is determined by dynamic repeated load testing in laboratory. However, due to the limited number of laboratories specialized in this type test in the country, the technique called "retroanalysis" has been used, which, combined with the concepts of elasticity theory, obtain the RM from the thickness of the layers and the deflections measured in the surface of the pavement.

Traditional retroanalysis is an iterative process; it does not generate a single solution and its results can be highly influenced by initial conditions and other variables. In order to overcome these constraints, it is possible to use Artificial Neural Networks (ANN), which are relatively new techniques, widely used to solve nonlinear problems and that apply to several areas of knowledge, including pavement engineering, with satisfactory results.

Given the situation described above, this paper aims to present a study on the RM retroanalysis of paving materials using ANN as an alternative to traditional retroanalysis. The study was conducted on $130 \mathrm{~km}$ of the BR-304 highway in the state of Rio Grande do Norte, with about 3,200 field-measured deflection basins.

\section{RETROANALYSIS}

Retroanalysis is a process that is based on the interpretation of the shape and magnitude of the displacement of the pavement surface (deflectometric basin) when it is subjected to loads (Albernaz et al., 1995 and Nóbrega, 2003). From the concepts of the Boussinesq and Burmister elasticity theory and the deflectometric basins, it is possible to obtain a more accurate diagnosis of the structural conditions of the pavement by obtaining its elastic characteristics, for example, the resilience modules of the constituent materials of each layer. (Rocha Filho and Rodrigues, 1996, Nóbrega, 2003).

\subsection{Retroanalysis methods}

Currently retroanalysis methods fall into two groups: iterative and simplified. The iterative methods are those whose determination of the elastic and geometrical characteristics of the pavement layers are performed by comparing the deflectometric basin obtained in field and the theoretical of a series of structures. The process ends until the field deflections are the same as those obtained for theoretical basin or has a permissible residue which is defined at the beginning of the process. However, because iterative processes are used in the convergence of its own solution, they require a lot of processing time and, depending on the number of analysis passages, this process can take hours or even days to complete (Albernaz et al., 1995 and Nóbrega, 2003).

In turn, the simplified methods are characterized by using equations, tables and graphs, among other simplifications of the theory of elasticity applied to homogeneous, isotropic and linearly elastic media. According to Albernaz (1997), these methods generally convert the multilayer structures into simpler one-, two- or three-layer structures, already considering the subgrade. They lose accuracy due to simplification; however, they gain in processing time calculations of the elastic parameters of the structure. 
Given the limitations of the methods described before, ANN have been applied in various fields of pavement engineering, including the retroanalysis of paving materials, with favorable results between actual and predicted values.

Coutinho Neto (2000) applied ANN into retroanalysis, composed of an input layer with artificial deflection basin, radius of curvature and the thickness of the pavement layers. The exit layer consisted of the RM of the pavement layers. Six ANN were implemented: two simulating the two-layer procedure (one simulating the Benkelman Beam test and the other the Falling Weight Deflectometer - FWD), two for the three-layer pavement (simulation with the same devices) and two for the four-layer pavement (simulating the tests described above). Through linear regressions between the real RM and those predicted by the ANN, coefficients of determination $\left(\mathrm{R}^{2}\right)$ that demonstrated a good linear correlation between the real RM were obtained. (Zanetti, 2008).

Macedo (2003) developed statistical analysis and ANN in the comparison of retroanalyzed RM from basins obtained with Benkelman Beam and FWD with real RM. The results showed that the $\mathrm{R}^{2}$ obtained by ANN analysis were, in general, higher than the $\mathrm{R}^{2}$ obtained by statistical analysis. Even in cases whose $\mathrm{R}^{2}$ obtained in the statistical analysis was better than in the ANN analysis, the correlations obtained by the latter, unlike the statistical correlations, allow its extrapolation.

In turn, Zanetti (2008) used the ANN to obtain the RM of the three- and four-layer pavement layers, from the retroanalysis of simulated theoretical basins in a mechanistic analysis program, as well as deformation stresses on the underside of the wearing course and the tension at the top of the subgrade for predicting the pavement lifespan. The results obtained were very satisfactory, with a correlation level between real and predicted ANN variables of at least $97.6 \%$.

\section{ARTIFICIAL NEURAL NETWORKS (ANN)}

ANN is one of the branches of artificial intelligence that seeks to develop computational models inspired by the functioning of the human brain (Zanetti, 2008). Such models are a simple composition of processing units (neurons) interconnected by connections known as "artificial synapses" (Haykin, 2001 and Godoy et al., 2013).

The working principle of ANN is its ability to learn from examples, the so-called "supervised learning", which initially consists of presenting a sufficient set of samples to the network, called a "training set", which includes all inputs and their respective desired outputs. Thus, through a learning algorithm, the network uses this set for self-training, adjusting, at each iteration, the weights of its layer neurons until the network response approaches the known desired output. The algorithm-stopping criterion is defined by the mean square error between the network responses and the desired output.

Ribeiro (2016) made use of ANN techniques in the generation of models to estimate soil RM, so that they can be used in pavement design methods. The results showed that the ANN are able to predict with good accuracy, with a coefficient of correlation of 0.984 , the soil RM values, showing promising use of neural models to predict the RM for the mechanistic-empirical design of soil. For the author, this technique allows the use of the models generated in the pavements design, in the absence of information or scarcity of financial resources for road projects.

An ANN extracts its maximum computational potential through its structure and its ability to learn and generalize. Such networks produce adequate outputs even if they receive inputs that were not in the training process, so they can even interpret false readings without altering 
results. ANN can be employed for pattern classification, time series analysis, data mining, data grouping, and result estimation based on previously acquired knowledge and its generalizability of situations (Haykin, 2001 and Godoy et al., 2013).

\subsection{Multilayer Perceptron Network (MLP)}

According to Zanetti (2008), Multilayer Perceptron ANN (MLP) are the most widely used ones today because they are very versatile and capable of solving problems from the simplest to the most complex. In MLP-like networks, shown in Figure 1, the intermediate layers are inserted between the input and output layers. The first layer of an MLP network consists of input units with independent variables $\left(\mathrm{x}_{\mathrm{i}}\right)$. The last layer contains output units, associated with the dependent variables $\left(\mathrm{y}_{\mathrm{i}}\right)$. All other units in the model are called "hidden units" and constitute the intermediate layers.

The structure presented in Figure 1 is proposed in a wide range of applications and can be used as universal function approximator, pattern classification, system identification, optimization, process control and others (Haykin, 2001 and Godoy et al., 2013). Their training is supervised, enabling the network to properly adjust the weights through an algorithm called Backpropagation (retroerror propagation) to better meet the objectives. (Godoy et al., 2013).

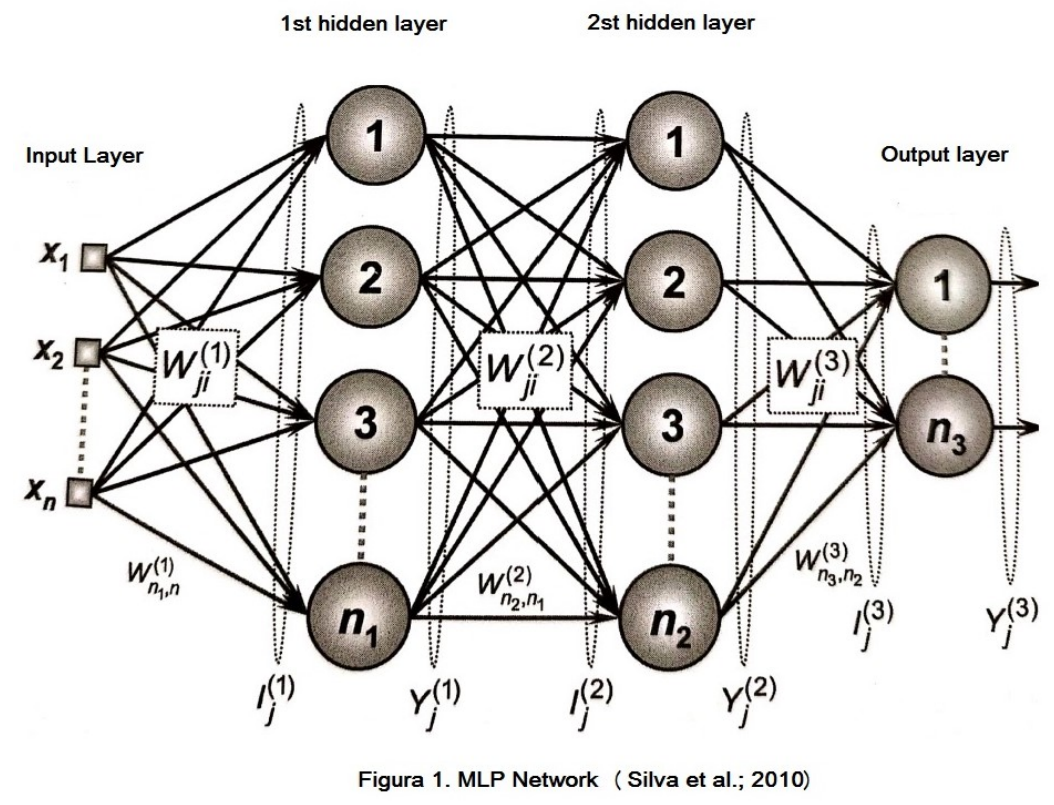

Figure 1. MLP Network (Silva et al., 2010)

\subsection{Levenberg - Marquardt Method}

The Backpropagation algorithm adjusts the values of the MLP network weight matrices in the opposite direction of the quadratic error function; however, the use of this algorithm tends to converge very slowly, requiring high computational effort. To circumvent the problem, various optimization techniques have been incorporated into the Backpropagation algorithm to reduce its convergence time and decrease the computational effort required. The Levenberg-Marquardt algorithm is a second order gradient method based on the least squares method for nonlinear models that can be incorporated into the Backpropagation algorithm to enhance training process efficiency (Silva et al., 2010). 
The implementation of these changes by the Levenberg-Marquardt method in the conventional Backpropagation algorithm can conduct network training 10 to 100 times faster than the traditional algorithm (Hagan and Menhaj, 1994 and Silva et al., 2010).

\section{MATERIALS AND METHODS}

Initially, a highway that had deflection data measured in the field had to be found. The highway chosen was BR-304, in Rio Grande do Norte, between Km 15 and Km 280. In this section, the National Department of Transport Infrastructure has field measurements of 3,232 deflectometric basins made with the FWD. Table 1 shows the database model provided by the FWD assay that was used in this paper. The data correspond to the measurement station location, applied load, deflections at distances of $0,20,30,45,60,90$ and $150 \mathrm{~cm}$ from the point of application of the load, pavement and air temperature and radius of curvature of the deflectometric basins.

Table 1 - FWD Assay Database Model - BR-304 / RN Highway

\begin{tabular}{|c|c|c|c|c|c|c|c|c|c|c|c|c|c|}
\hline \multirow[b]{2}{*}{$\begin{array}{l}\mathrm{Ba} \\
\mathrm{si} \\
\mathrm{n}\end{array}$} & \multicolumn{2}{|c|}{ Location } & \multirow[b]{2}{*}{$\begin{array}{c}\text { Loading } \\
\text { (Kgf) }\end{array}$} & \multicolumn{7}{|c|}{ DEFLECTION $\left(1 \times 10^{-2} \mathrm{~mm}\right)$} & \multicolumn{2}{|c|}{ TEMP. ( $($ C) } & \multirow[b]{2}{*}{$\begin{array}{l}\text { CR } \\
\text { (m) }\end{array}$} \\
\hline & km & $\begin{array}{l}\text { Side } \\
\mathrm{R} / \mathrm{L}\end{array}$ & & $\begin{array}{c}\text { FWD } \\
\text { D0 } \\
(0 \mathrm{~cm})\end{array}$ & $\begin{array}{l}\text { FWD D1 } \\
(20 \mathrm{~cm})\end{array}$ & $\begin{array}{l}\text { FWD D2 } \\
(30 \mathrm{~cm})\end{array}$ & $\begin{array}{l}\text { FWD D3 } \\
(45 \mathrm{~cm})\end{array}$ & $\begin{array}{c}\text { FWD } \\
\text { D4 } \\
(60 \\
\mathrm{cm}) \\
\end{array}$ & $\begin{array}{c}\text { FWD } \\
\text { D5 } \\
\text { (90 } \\
\text { cm) }\end{array}$ & $\begin{array}{c}\text { FWD } \\
\text { D6 } \\
(150 \\
\mathrm{cm})\end{array}$ & Pav. & Air & \\
\hline 1 & 150,00 & RS & 43,26 & 59,64 & 47,22 & 37,44 & 24,09 & 16,38 & 7,38 & 2,15 & 29,50 & 26,00 & 180,53 \\
\hline 2 & 150,04 & RS & 41,21 & 47,69 & 37,88 & 30,66 & 19,81 & 12,81 & 5,81 & 1,57 & 29,70 & 26,00 & 232,86 \\
\hline 3 & 150,08 & RS & 39,87 & 69,87 & 54,67 & 40,02 & 24,29 & 14,93 & 5,60 & 0,42 & 29,70 & 26,00 & 138,73 \\
\hline 4 & 150,12 & RS & 40,28 & 66,12 & 51,04 & 34,07 & 22,00 & 12,89 & 5,62 & 1,30 & 29,10 & 26,00 & 132,61 \\
\hline 5 & 150,16 & RS & 39,62 & 68,64 & 54,14 & 41,54 & 24,09 & 13,70 & 3,62 & 0,21 & 30,00 & 26,10 & 150,24 \\
\hline 6 & 150,20 & RS & 39,44 & 66,05 & 50,61 & 33,33 & 17,03 & 6,91 & 1,05 & 0,00 & 29,30 & 26,10 & 129,78 \\
\hline 7 & 150,24 & RS & 40,74 & 58,66 & 44,07 & 32,56 & 16,59 & 9,90 & 2,85 & 1,25 & 29,90 & 26,20 & 153,60 \\
\hline 8 & 150,28 & RS & 39,62 & 53,15 & 40,23 & 31,41 & 19,12 & 12,72 & 5,95 & 1,90 & 30,40 & 26,60 & 180,32 \\
\hline 9 & 150,32 & RS & 40,96 & 36,82 & 29,06 & 21,89 & 12,73 & 7,29 & 1,85 & 0,60 & 30,70 & 26,60 & 275,45 \\
\hline 10 & 150,36 & RS & 39,50 & 64,98 & 51,01 & 40,10 & 25,37 & 16,93 & 6,80 & 0,97 & 30,30 & 26,70 & 160,88 \\
\hline
\end{tabular}

In addition to pavement deflections, layer thicknesses were made available from the executive design of the highway under construction. The highway has layers whose average thickness is $5 \mathrm{~cm}$ of Asphalt Concrete, $19.4 \mathrm{~cm}$ of granular base and $20 \mathrm{~cm}$ of granular sub-base. The subgrade for calculation purposes is considered as a semi-space of infinite thickness.

For the case under study, the ANN training sample set has, as input data, the thickness of the pavement layers and the deflection basins measured on the surface. On the other hand, the desired outputs were the respective RM of each pavement layer for each deflection measuring station performed. In this sense, due to the difficulty of obtaining these RM through repeated load triaxial tests and the large number of deflectometric basins, a traditional backanalysis was initially used to obtain the RM set of all 3,232 basins measured by FWD. For this, the subroutine Retroanalysis of the SISPAV program was used (Franco, 2007).

The program performs the backanalysis of the RM from the layer thicknesses and the deflectometric basins measured in the field. It also performs the back analysis of the Poisson's ratio values of the materials that compose each layer, the pavement temperature, the applied load and the variation interval between the layers of minimum and maximum values of the RM. All these data are available in the FWD results, except for Poisson's coefficients and minimum and maximum RM values. For these, values recommended in the established given material literature were used. The values are presented in Table 2. 
Table 2 - Maximum and Minimum Resilience Modules and Poisson's Coefficients

\begin{tabular}{llll}
\hline Layer & RMmin. (MPa) & RMmax. (MPa) & Poisson Coef. (MPa) \\
\hline Wearing course & 1500 & 3500 & 0,30 \\
Base & 150 & 400 & 0,35 \\
Subbase & 150 & 350 & 0,35 \\
Sublayer & 50 & 150 & 0,40 \\
\hline
\end{tabular}

After providing the data, the program performs several iterations with the field-obtained basins in order to fit with any of the theoretical structure basins previously calculated in the program database that already have their respective RM.

It was not the objective of this paper to fine-tune the FWD field-measured basins and the program-calculated theoretical basins in order to minimize the error between the measured and calculated deflection values. With the Retroanalysis, it was only attempted to obtain the set of RM values corresponding to each theoretical basin provided. Therefore, the theoretical basins and their respective RM were taken as input and output data, respectively, for the implemented RNA training. The theoretical basins were considered as real basins of pavement surface deflections and the corresponding RM were also considered as the reference pavement RM. These reference values, therefore, were compared with the RM values analyzed by the RNA in the training phase.

For the implementation of the ANNs, the MATLAB software was used. There are two ways to build ANN in MATLAB, one is by writing the algorithm code using the ANN toolboxes inserted into the program. The other way is to use the NNtool tool, which is an easy-to-use user-friendly graphical interface, where the user is provided with the desired input and output data for neural network training, the choice of training algorithm, the activation function, the number of neurons in each layer, training parameters and stopping criteria.

Four artificial neural networks were created for the wearing course, base, sub-base and sublayer layers to predict, from the inputs provided, the respective RM. The characteristics of each of the implemented networks are shown in Table 3.

Table 3 - Characteristics of implemented RNAs

\begin{tabular}{lllll}
\hline CARACTERÍSTICA & WEARING COURSE & BASE & SUB-BASE & SUBLAYER \\
\hline ARCHITECTURE & MLP & MLP & MLP & MLP \\
No. INTERMEDIATE LAYERS & 2 & 2 & 2 & 2 \\
№ 1st LAYERS NEURONS & 18 & 15 & 20 & 10 \\
№ 2nd LAYERS NEURONS & 9 & 10 & 16 & 5 \\
TRAINING ALGORITHM & LM & LM & LM & LM \\
1st LAYER ACTIVATION FUNCTION & TANSIG & TANSIG & TANSIG & TANSIG \\
2nd LAYER ACTIVATION FUNCTION & TANSIG & TANSIG & TANSIG & TANSIG \\
EXIT LAYER ACTIVATION FUNCTION & TANSIG & TANSIG & TANSIG & TANSIG \\
STOPPING CRITERION & MSE & MSE & MSE & MSE \\
EPOCH NUMBER & 10.000 & 10.000 & 10.000 & 10.000 \\
\hline
\end{tabular}

The set samples division for subsets training, validation, and test was randomized. From the total of samples, $70 \%$ were used for the training phase, $15 \%$ for the validation phase and $15 \%$ for the test phase. The weights of the ANN-adjusted neurons in the training phase were validated and tested using their respective sample sets, different from those used in training. The predicted values (calculated modules) by the ANN were compared with the reference RM 
obtained in the Retroanalysis. Finally, the percentage error between the predicted and the reference RM, the mean square error, the regression lines and the correlation between these values were obtained.

\section{RESULTS}

Before presenting the numerical results of the pavement RM analyzed by the ANN, Table 4 and Figure 2 present the statistical results of the considered three-layer pavement. They also present the coefficients of determination $\left(R^{2}\right)$ and the regression lines relating the reference and predicted RM by the ANNs for each of the training, validation and testing phases, as well as for the total sample set.

Table 4 - Coefficients of Determination $\left(R^{2}\right)$ between real and predicted RNA modules

\begin{tabular}{lllll}
\hline PAVEMENT LAYER & TRAINING $\left(\mathbf{R}^{\mathbf{2}}\right)$ & VALIDATION $\left(\mathbf{R}^{\mathbf{2}}\right)$ & TEST $\left(\mathbf{R}^{\mathbf{2}}\right)$ & TOTAL $\left(\mathbf{R}^{\mathbf{2}}\right)$ \\
\hline Wearing course & 0,99998 & 0,99990 & 0,99926 & 0,99986 \\
Base & 0,99966 & 0,99912 & 0,99968 & 0,99958 \\
Subbase & 1,00000 & 0,99980 & 0,99920 & 0,99986 \\
Sublayer & 1,0000 & 0,99980 & 1,0000 & 1,0000
\end{tabular}
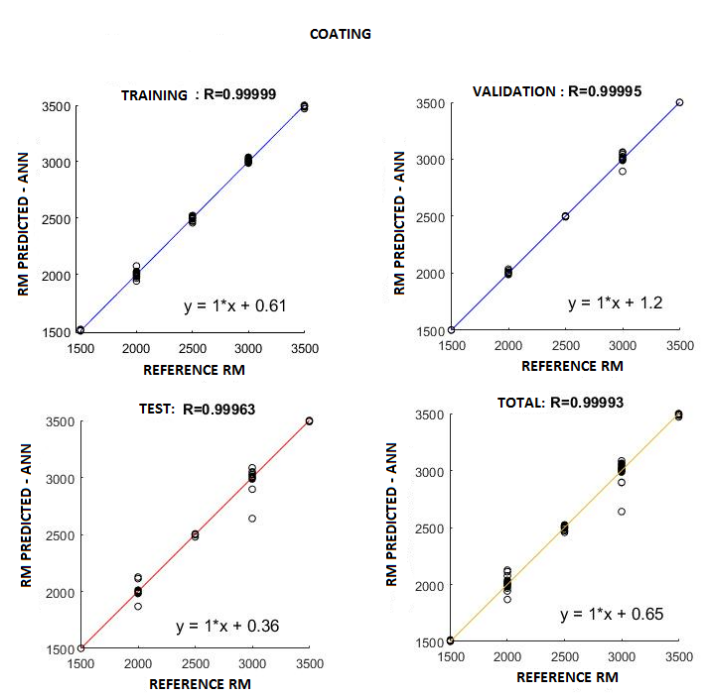

SUBBASE
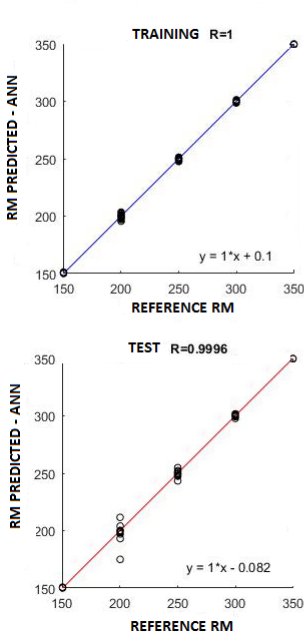
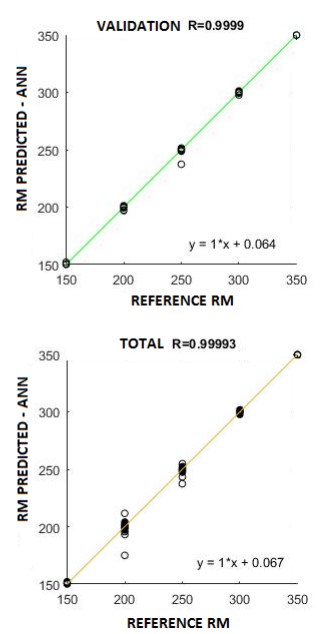

BASE
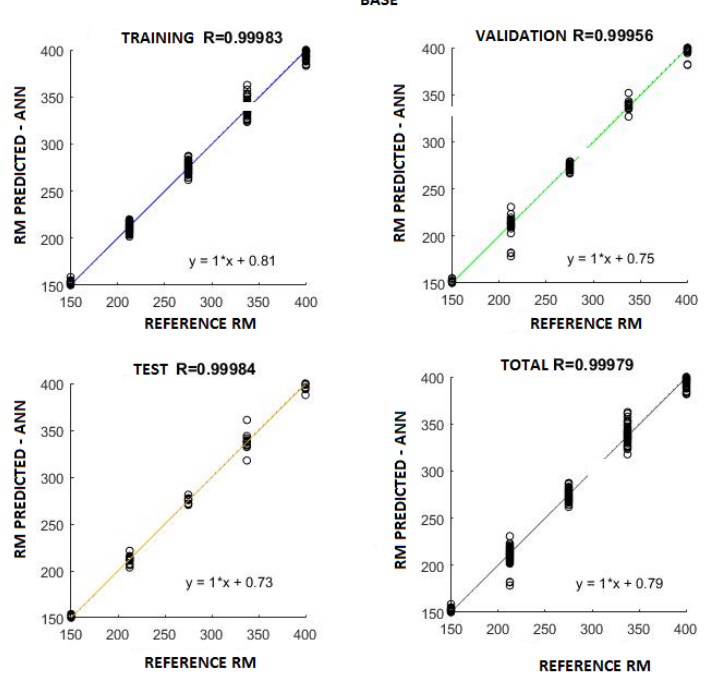

SUBLAYE
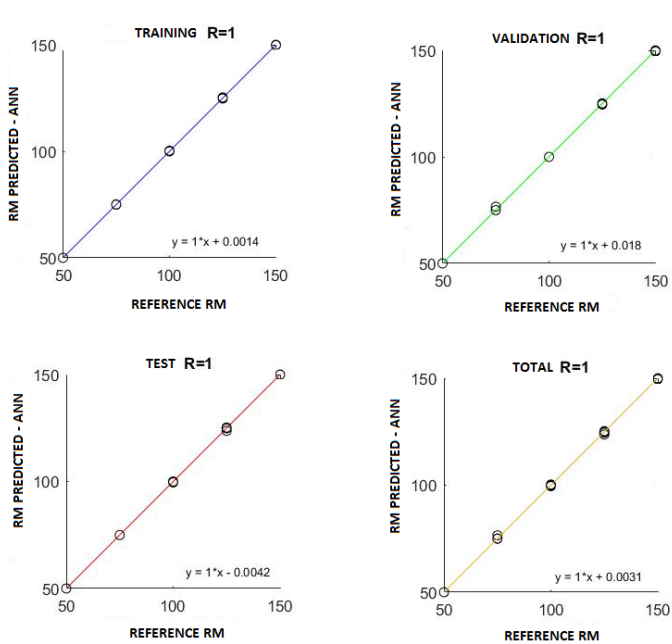

Figura 2. Regression lines between reference and predicted RMs 
Wearing course

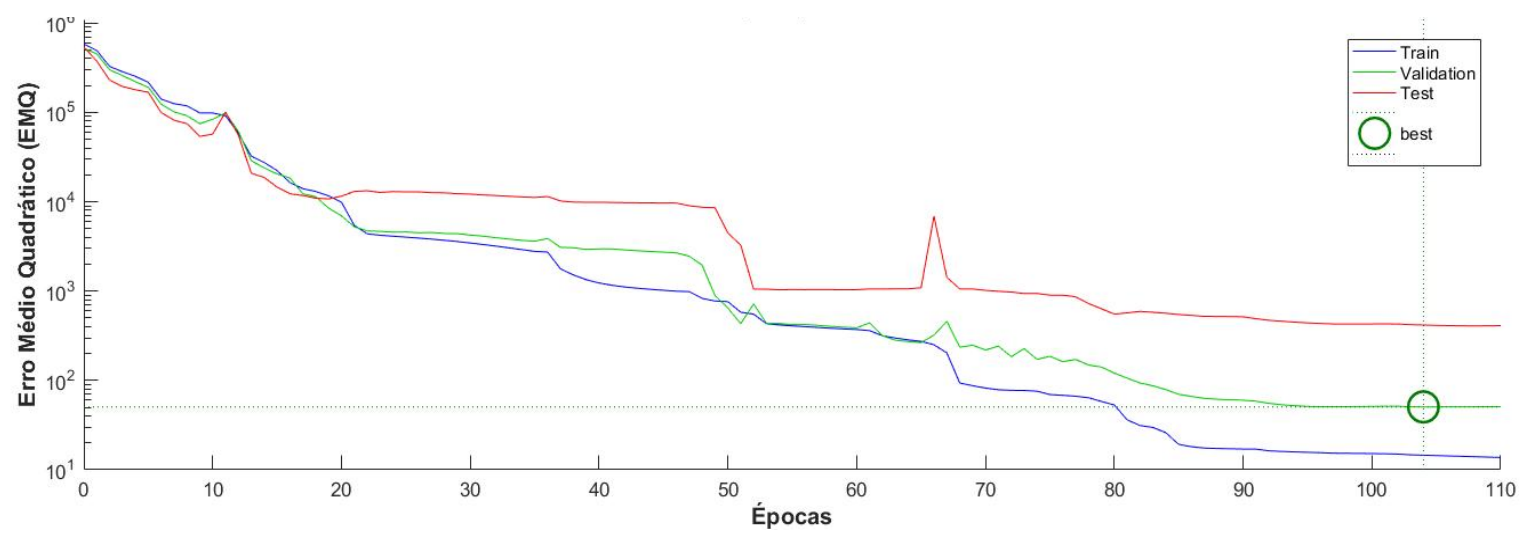

Base

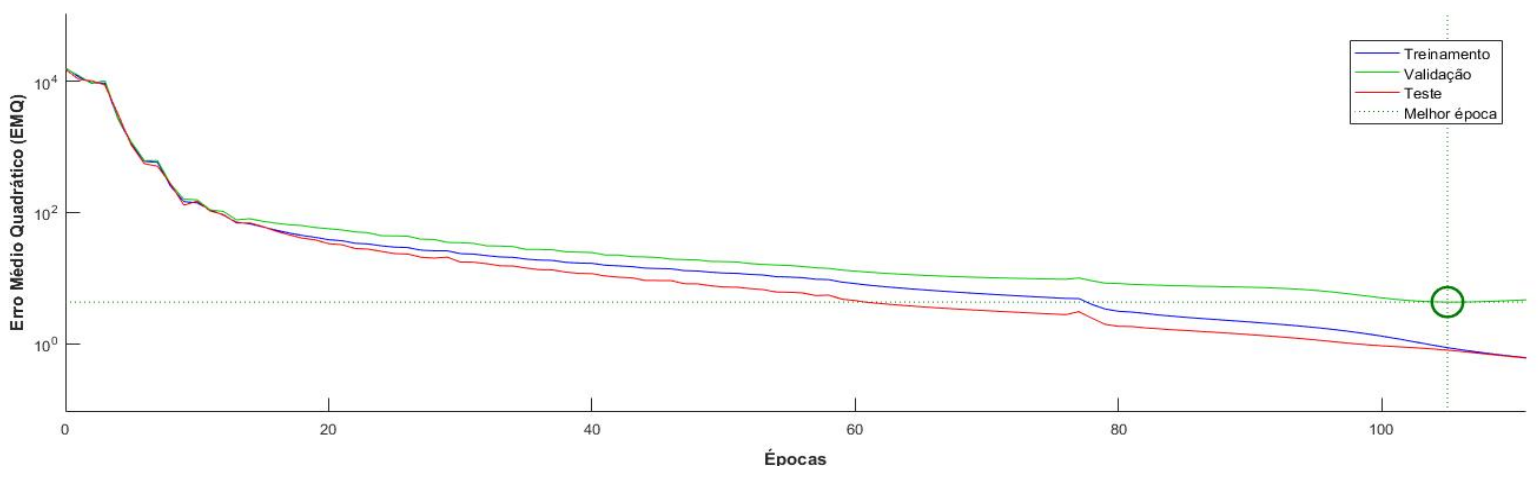

Sub-base

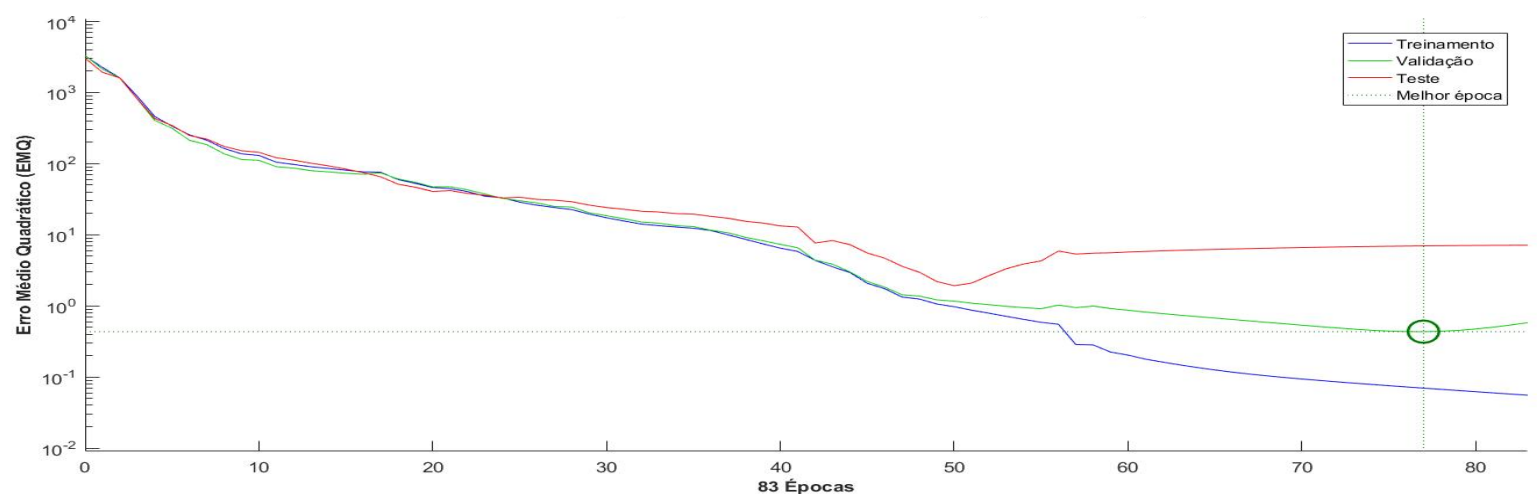

Sub-grade

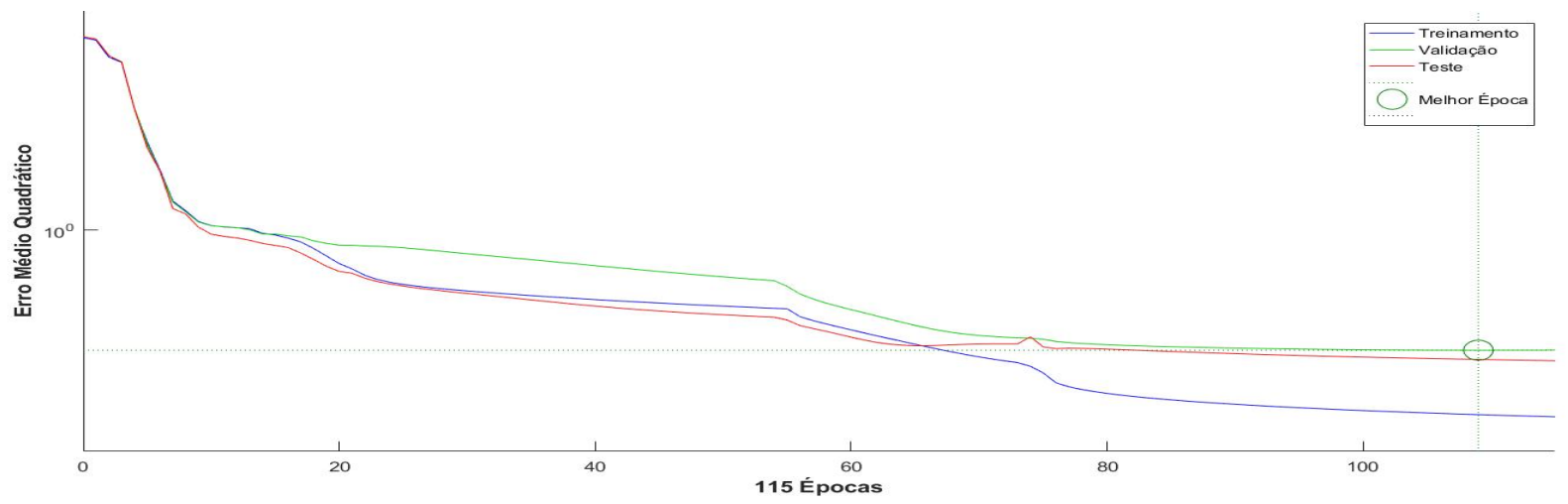

Figure 3. Mean Squared Error - MSE 
Figure 2 shows the strong linear relationship between reference and predicted RM. The coefficients of determination $\left(\mathrm{R}^{2}\right)$ in the order of 0.999 to 1.000 between the reference and predicted RM for the constituent pavement layers, in all phases (training, validation and tests), confirm the prediction capacity of the implemented ANN. Figure 3 shows the performance of the networks (Mean Squared Error - MSE) between the reference and predicted values in the training, validation and testing phases for all pavement layers.

Analyzing the graphs in Figure 3, one can observe that the stopping criterion of the training algorithm was exactly the times when the validation phase MSE began to increase compared to the training phase MSE, in order to avoid the Overfitting phenomenon of the synaptic weights.

The MSE corresponding to the observed downtime were considered acceptable, since, according to Table 5, which shows the results of basins 1 to 35, the numerical values of the predicted RM were practically equal to the values of the reference modules. Percentage errors in more than $93 \%$ of cases were less than $1 \%$ when comparing the reference and predicted RM.

Table 5 - Reference and Predicted RM values by ANN

\begin{tabular}{|c|c|c|c|c|c|c|c|c|c|c|c|c|}
\hline \multirow[b]{2}{*}{ Basin } & \multicolumn{3}{|c|}{ RM Wearing course (MPa) } & \multicolumn{3}{|c|}{ RM Base (MPa) } & \multicolumn{3}{|c|}{ RM Sub-base (MPa) } & \multicolumn{3}{|c|}{ RM Subgrade (MPa) } \\
\hline & Ref. & Predicted & Error (\%) & ef. & Predicted & Error (\%) & Ref. & Predicted & $\begin{array}{c}\text { Error } \\
(\%)\end{array}$ & ef. & Predicted & $\begin{array}{c}\text { Error } \\
(\%)\end{array}$ \\
\hline 1 & 00,00 & & & 0,00 & & & 0,00 & & $-0,01 \%$ & 150,00 & & $0,00 \%$ \\
\hline 2 & 00,00 & 500,00 & $00 \%$ & 00,00 & 399,75 & & 350,00 & 9,96 & $-0,01 \%$ & 150,00 & & $00 \%$ \\
\hline 3 & 00,00 & & & 00,00 & & & 50,00 & & $0,01 \%$ & 150,00 & & \\
\hline 4 & 500,00 & & & 400,00 & 9,72 & $37 \%$ & 350,00 & 349,96 & $-0,01 \%$ & 150,00 & & $00 \%$ \\
\hline 5 & 00,00 & & & 400,00 & & & 350,00 & & $-0,01 \%$ & 150,00 & & \\
\hline 6 & 00,00 & & & 400,00 & & & 350,00 & & & 150,00 & & \\
\hline 7 & 3500,00 & & & 400,00 & 9,72 & & 350,00 & & $-0,01 \%$ & 150,00 & & \\
\hline 8 & 500,00 & & & 337,50 & & & 250,00 & & & 150,00 & & \\
\hline 9 & 500,00 & & & 400,00 & & & 150,00 & & & 150,00 & & \\
\hline 10 & 500,00 & & & 400,00 & & & 150,00 & & $\%$ & 150,00 & & $1 \%$ \\
\hline 11 & 00,00 & & & 400,00 & & & 350,00 & & & 150,00 & & \\
\hline 12 & 500,00 & & & 400,00 & & & 350,00 & & & 150,00 & & \\
\hline 13 & 3500,00 & & & 400,00 & & & 350,00 & & -0 & 150,00 & & $0 \%$ \\
\hline 14 & 3500,00 & & & 400,00 & & & 350,00 & & & 150,00 & & \\
\hline 15 & 3500,00 & & & 400,00 & & & 350,00 & & & 150,00 & & \\
\hline 16 & 0,00 & & & 400,00 & & & 350,00 & & & 150,00 & & \\
\hline 17 & 3500,00 & & & 400,00 & & & 350,00 & & & 150,00 & & \\
\hline 18 & 3500,00 & & & 400,00 & & & 350,00 & & & 150,00 & & $\%$ \\
\hline 19 & 3500,00 & & & 400,00 & & & 350,00 & & & 150,00 & & \\
\hline 20 & 3500,00 & & & 275,00 & & & 350,00 & & & 150,00 & & \\
\hline 21 & 1500,00 & & & 150,00 & & & 150,00 & & & 125,00 & & \\
\hline 22 & 3500,00 & & & 150,00 & & & 350,00 & & & 150,00 & & \\
\hline 23 & 3500,00 & & & 212,50 & & & 350,00 & & & 150,00 & & \\
\hline 24 & 3500,00 & & & 150,00 & & & 350,00 & & & 150,00 & & \\
\hline 25 & 3500,00 & & & 212,50 & & & 300,00 & & & 150,00 & & $0 \%$ \\
\hline 26 & 1500,00 & & & 150,00 & & & 150,00 & & & 150,00 & & \\
\hline 27 & 3500,00 & 0 & & 150,00 & & & 250,00 & & $\%$ & 150,00 & & \\
\hline 28 & 3500,00 & & & 212,50 & & & 350,00 & & $-0,02 \%$ & 150,00 & & $0 \%$ \\
\hline 29 & 3500,00 & & & 150,00 & & & 350,00 & & & 150,00 & & \\
\hline 30 & 3500,00 & 85 & & 150,00 & 04 & & 200,00 & 93 & $-0,04 \%$ & 150,00 & 88 & $01 \%$ \\
\hline 31 & 3500,00 & 3500,00 & & 212,50 & & $16 \%$ & 300,00 & & $6 \%$ & 150,00 & & $00 \%$ \\
\hline 32 & 3500,00 & & & 150,00 & & & 300,00 & & & 150,00 & & \\
\hline 33 & 3500,00 & & & 400,00 & & & 350,00 & & $-0,01 \%$ & 150,00 & 149,99 & $0,00 \%$ \\
\hline 34 & 500,00 & & & 400,00 & & & 350,00 & & & 150,00 & & $0,00 \%$ \\
\hline 35 & 1500,00 & 502,17 &, $14 \%$ & 337,50 & 337,35 & $-0,05 \%$ & 150,00 & 150,02 & $0,02 \%$ & 150,00 & 149,99 & $-0,01$ \\
\hline
\end{tabular}


An effective prediction of the retroanalyzed RM by the basins of deflections and thicknesses of the studied pavement layers is also due to the treatment, quantity and quality of these data. The thicknesses of the wearing course, base and sub-base layers were the actual thicknesses performed during the highway implementation, obtained from the executive project. According to Albernaz (1997), the final RM of the structure is highly influenced by the thickness of its layers, because if the thickness adopted for a layer is smaller than the actual thickness, the retroanalyzed RM may be significantly larger than the correct layer RM to compensate the value of the equivalent stiffness (RM and thickness function) of the layer. The opposite would happen if the thickness adopted were larger than the actual one.

The deflection basins and the respective RMs of the set of samples used for ANN training proved to be consistent and adequate for adjusting the weights of the hidden layers of the ANN, since, applying them to the validation and testing set, they predicted satisfactorily the reference RM of the pavement layers of the analyzed highway. A possible presence of inconsistent thickness data, deflection and RM could contribute to poor network performance in the training phase and, consequently, an unsatisfactory prediction of pavement layer RMs in subsequent phases.

It is important to emphasize the difference in the processing time verified between the two retroanalysis methodologies. The traditional method, through the retroanalysis program, required hours to retro analyze the RM of all 3,232 FWD field-measured deflection basins. The ANN required seconds or a few minutes, at most, to perform all network training, which used $70 \%$ of the 3,232 raised deflection basins, i.e., 2,262 basins.

\section{CONCLUSION}

The responses of Artificial Neural Networks (ANN) against the objective of predicting the Resilience Modules (RM) of paving materials from the deflection basins and the thickness of their layers, proved their efficacy and applicability in the retroanalysis process. In addition to the processing time gain compared to traditional retroanalysis, stands out the power of generalization and prediction of ANN.

Generalization capacity was verified by analyzing the results of the coefficients of determination $\left(\mathrm{R}^{2}>0.999\right)$ between the actual and predicted $\mathrm{RM}$ obtained for the test subset. Thus, it can be stated that the RM can be retroanalyzed for any structure using the weights adjusted in the training phase, if the maximum and minimum values of the RM of these structures are within the data/subset universe used in the training network.

Percentage errors of less than $1 \%$ in at least $93 \%$ of cases demonstrated the predictability of the implemented artificial neural networks. It is noteworthy that the good performance of the ANN, especially in the training phase, depends on the consistency, quantity and quality (minimum noise) of the available sample data set, because using a very small sample set, especially in the training phase, can compromise the proper adjustment of neuron weights during processing, which may impair the network's ability to learn. On the other hand, however, having a large amount of data, with a large number of inconsistencies, affects the quality of the network result.

In addition to the consistency, quality and quantity of samples available, the number of hidden layers and the respective numbers of neurons influence neural network performance. Before defining the final architecture of the networks implemented in this paper, several attempts were made to obtain satisfactory topologies, that is, the appropriate number of neurons and 
layers to obtain a good fit. However, one cannot state that the chosen topology is the best of several possible combinations, as better or worse results can be obtained by trying to choose other combinations of number of neurons and hidden layers.

Along these lines, considering the results of this paper for the section under study, it can be stated that the applicability of ANN in the retroanalysis process proved to be very effective and efficient, depending on the predicted RM values and the observed processing time, in the hases of training, validation and testing during backanalysis.

\section{REFERENCES}

Albernaz, C. A. V. (1997) Simplified Method of Retrofitting Flexible Pavement Resilience Modules from the Deflection Basin. Master's Thesis, Coppe - The Alberto Luiz Coimbra Institute for Graduate Studies and Research in Engineering, Federal University of Rio de Janeiro, Rio de Janeiro.

Albernaz, C. A. V.; L. M. G. Motta and J. Medina (1995) Retroanalysis: A Useful Tool in Structural Pavement Evaluation. Proceedings of the 29th Annual Paving Meeting. Cuiabá, v. 1, p. 399 - 417.

Bernucci, L. B.; L. M. G. Motta; J. A. P. Ceratti and J. B. Soares (2006) Asphalt Paving: basic training for engineers. 1st ed. Petrobras: Abeda, Rio de Janeiro.

Coutinho Neto, B. (2000) Artificial neural networks as a procedure for flexible pavement retroanalysis. Master's Thesis. São Carlos School of Engineering. University of Sao Paulo, Sao Carlos. Available in: <https://www.teses.usp.br/teses/disponiveis/18/18137/tde-01022018-122501/pt-br.php> (access in 23/12/2019).

Franco, F. A. C. P. (2007) Method of Mechanical-Empirical Dimensioning of Asphalt Pavements - SisPav. Doctoral Thesis. Coppe The Alberto Luiz Coimbra Institute for Graduate Studies and Research in Engineering, Federal University of Rio de Janeiro, Rio de Janeiro. Available in: <http://www.coc.ufrj.br/pt/teses-de-doutorado/151-2007/1107-filipe-augusto-cinque-deproenca-franco> (access in 23/12/2019).

Godoy, W. F.; I. N. Silva; W. S. Gongora; A. Goedtel and R. H. C. Palaces (2013) Failure Classification in Three-Phase Induction Motor Bearings using Artificial Neural Networks. Proceedings of the XI Brazilian Symposium on Intelligent Automation, Fortaleza. Available in: <http://www.sbai2013.ufc.br/pdfs/4788.pdf> (access in 23/12/2019).

Hagan, M.T. and M. B. Menhaj (1994) Training Feedforward Networks with the Marquardt Algorithm. IEEE Transactions on Neural Networks, v. 5, n. 6, p. 989 - 993. DOI: 10.1109/72.329697.

Haykin, S. (2001). Neural Networks: Principles and Practices. 2nd edition. Bookman, Porto Alegre.

Macedo, F. N. (2003) Retroanalysis of real and theoretical deflection basins obtained by static and dynamic methods. Master's Thesis. University of Brasília, Brasília, DF.

Nóbrega, E. S. (2003) Comparison Between Asphalt Pavement Retroanalysis Method. Master's Thesis. Coppe - The Alberto Luiz Coimbra Institute for Graduate Studies and Research in Engineering, Federal University of Rio de Janeiro, Rio de Janeiro. Available in: <http://www.coc.ufrj.br/pt/dissertacoes-de-mestrado/103-msc-pt-2003/1835-eduardo-suassunanobrega $>$ (access in 23/12/2019).

Ribeiro, A. J. A. (2016) A prediction model of resilient modulus of soils in the state of Ceará for the purpose of paving. Doctoral Dissertation, Federal University of Ceará, Fortaleza. Available in: <http://www.repositorio.ufc.br/handle/riufc/18958> (access in 23/12/2019).

Rocha Filho, N. R. and R. M. Rodrigues (1996) Structural Evaluation of Pavements through Deflectometric Surveys. Proceedings of the 30th Annual Paving Meeting. Salvador, v. 3, p. 1119 - 1146.

Rosenblatt, F. (1958). The Perceptron: A Probabilistic Model for Information Storage and Organization in the Brain. Physiological Reviews, v. 65 (3), p. 386-408. DOI: 10.1037/h0042519.

Silva, I. N.; D. H. Spatti and R. A. Flauzino (2010) Artificial neural networks for engineering and applied sciences, Artliber, 1st edition, São Paulo, SP.

Zanetti, F. S. (2008) The Use of Artificial Neural Networks as a Tool to Assist in Determining the Life of Flexible Pavements. Master's Thesis. São Carlos School of Engineering. University of São Paulo, São Carlos, SP. Available in:

<https://teses.usp.br/teses/disponiveis/18/18143/tde-28042009-091916/en.php> (access in 23/12/2019). 